\title{
A contribuição da Nutrição para melhoria da qualidade de vida da população
}

O lançamento de cada número de uma revista científica é sempre algo a ser comemorado com entusiasmo, pois trata-se de uma grande contribuição daqueles que consagram boa parte de sua vida ao trabalho intelectual, à construção de novos conhecimentos e à divulgação do resultado de um esforço que, muitas vezes, fica restrito a poucos.

E é com enorme satisfação que apresentamos esta edição, inaugurando uma website atualizada, com novo layout, com diversas facilidades para os usuários e o registro do DOI (do inglês: Digital Object Identifier), ou seja, o Identificador de Objeto Digital que marca mais uma etapa evolutiva da RASBRAN. Com o registro do DOI, os trabalhos publicados poderão ser localizados e referenciados da maneira exata, dando maior visibilidade para a revista e para os autores dos artigos.

E o compromisso da RASBRAN se reforça a cada edição, levando a profissionais e à sociedade, resultados de estudos e pesquisas relevantes na área de nutrição. Nesta edição o leitor observará uma diversidade de temas atuais que promovem a desnaturalização do que já está naturalizado, bem como levanta possibilidades de consensos e dissensos, todos pautados nos princípios éticos e em métodos científicos. Uma variedade que eleva o debate atinente à complexidade do tema nutrição na sociedade atual.

Alguns temas, mesmo relacionados a doenças mais comumente estudadas pelos profissionais da nutrição, como o diabetes mellitus, trazem um olhar diferenciado, como podemos verificar nos artigos "Atividades de autocuidado nutricional entre indivíduos com diabetes tipo 2" e "Excesso de peso e índice de conicidade em idosos com diabetes mellitus". No primeiro referencia-se o autocuidado, importante para que qualquer estratégia de tratamento dê certo e fundamental para se ter mais qualidade de vida e saúde, uma vez que é uma forma de fortalecer mente e corpo. E o segundo trazendo uma ferramenta mais específica para avaliação da distribuição da gordura corporal, o que possibilita comparar a magnitude da associação entre indicadores antropométricos como fatores de risco cardiometabólicos em uma população extremamente vulnerável, como os idosos.

O tratamento dietoterápico vem evoluindo ao longo das décadas, inclusive nas doenças neurológicas, como bem destacado nos artigos "Transtorno do Espectro Autista (TEA) e hipersensibilidade alimentar: perfil nutricional e prevalência de sintomas gastrointestinais" e "Avaliação do efeito do psyllium (plantago ovata) nos sintomas de dor em portadores de fibromialgia". Para os pacientes hospitalizados, a avaliação das dietas orais, ultrapassa a barreira dos macronutrientes calóricos, se especializa nos macrominerais como visto no artigo "Avaliação do teor de macrominerais em dietas hospitalares orais" e percorre fatores associados a problemas gastrointestinais comuns em pacientes acamados, como é o caso da 
constipação intestinal referendada no artigo "Constipação intestinal e fatores associados em pacientes internados em um hospital universitário".

Dietas específicas no tratamento de doenças crônicas também são relatadas nos artigos de Revisão. "A dieta cetogênica pode auxiliar no tratamento do câncer? Uma análise crítica" e "Contribuição da dieta eágua alcalina na redução de complicações da doença renal crônica", levando-nos a questionar a eficácia terapêutica e a verdadeira contribuição para a saúde do paciente - o que nos remete a necessidade de mais estudos sobre o uso indiscriminado destas dietas.

A preocupação dos profissionais com a alimentação adequada é evidenciada nos artigos "Características da gravidez e lactação de mulheres atendidas em um banco de leite humano" e "Consumo da alimentação escolar e qualidade da dieta de escolares", demonstrando que uma alimentação equilibrada faz toda a diferença na saúde das pessoas, independentemente de sua faixa etária e seu cuidado deve ser iniciado desde a gestação.

Ainda sob essa preocupação, o artigo "Influência da marca na intenção de compra do consumidor de suco de laranja industrializado" nos traz uma forma legitima de questionarmos as escolhas por alimentos não tão saudáveis, mas que tem um apelo visual e uma estratégia de marketing tão forte que pode vir a moldar o comportamento do consumidor e influenciar completamente todo seu processo de decisão de compra. É preciso o profissional estar atento a essas influências negativas que podem afetar e muito a saúde das pessoas.

A percepção do profissional a respeito de sua própria atuação é o que motivou os autores do artigo "Percepção de nutricionistas sobre sua atuação profissional no contexto de supervalorização do corpo magro e escultural", tema bastante relevante uma vez que no nosso país há uma busca exacerbada pelo corpo perfeito em curto espaço de tempo, levando a extremos e podendo causar doenças graves e até a morte. É, pois, legitima e bastante necessária a preocupação e o entendimento que o profissional de nutrição tem em relação a esse contexto.

A segurança higiênico-sanitária é evidenciada no artigo "Análise do binômio tempo e temperatura de preparações à espera para distribuição em um restaurante universitário", demonstrando que os nutricionistas estão atentos aos cuidados necessários para a segurança do consumidor, bem como para o desperdício de alimentos, mencionado no Relato de caso "Atuação da Nutrição Clínica na redução de custos por produção de resíduos: economicidade em saúde", demonstrando assim que esta preocupação deve sobrepor a área específica de atuação, uma vez que é um tema de grande relevância e abrangência mundial para a Segurança Alimentar, a Nutrição e a Erradicação da Fome em nosso país.

Desejamos que a leitura desta revista seja proveitosa.

Ruth Cavalcanti Guilherme, Céphora Maria Sabarense e Ana Paula Ferreira da Silva Editoras 